\title{
Meconium pseudocyst
}

\author{
David Douglas
}

Received: 24 March 2010/Revised: 24 May 2010 /Accepted: 2 June 2010 /Published online: 24 June 2010

(C) The Author(s) 2010. This article is published with open access at Springerlink.com

A full-term infant presented with severe abdominal distention. Supine radiograph of the chest and abdomen show a large rim-calcified mass representing a meconium pseudocyst (Fig. 1, thick arrows). The irregular linear calcifications, mostly in the left upper quadrant, are calcified meconium in the peritoneal cavity adherent to bowel walls (small arrow). Surgical and pathological findings confirmed small bowel obstruction secondary to segmental volvulus with walled-off small-bowel perforation and pseudocyst formation.

Meconium peritonitis is caused by antenatal bowel perforation with spillage of meconium into the peritoneum causing a sterile peritonitis and formation of dystrophic calcifications [1]. Common causes of bowel obstruction and perforation include meconium ileus, bowel atresia, and segmental volvulus. When the extruded meconium becomes walled off, it can form a rim-calcified mass representing meconium pseudocyst [2].

Open Access This article is distributed under the terms of the Creative Commons Attribution Noncommercial License which permits any noncommercial use, distribution, and reproduction in any medium, provided the original author(s) and source are credited.

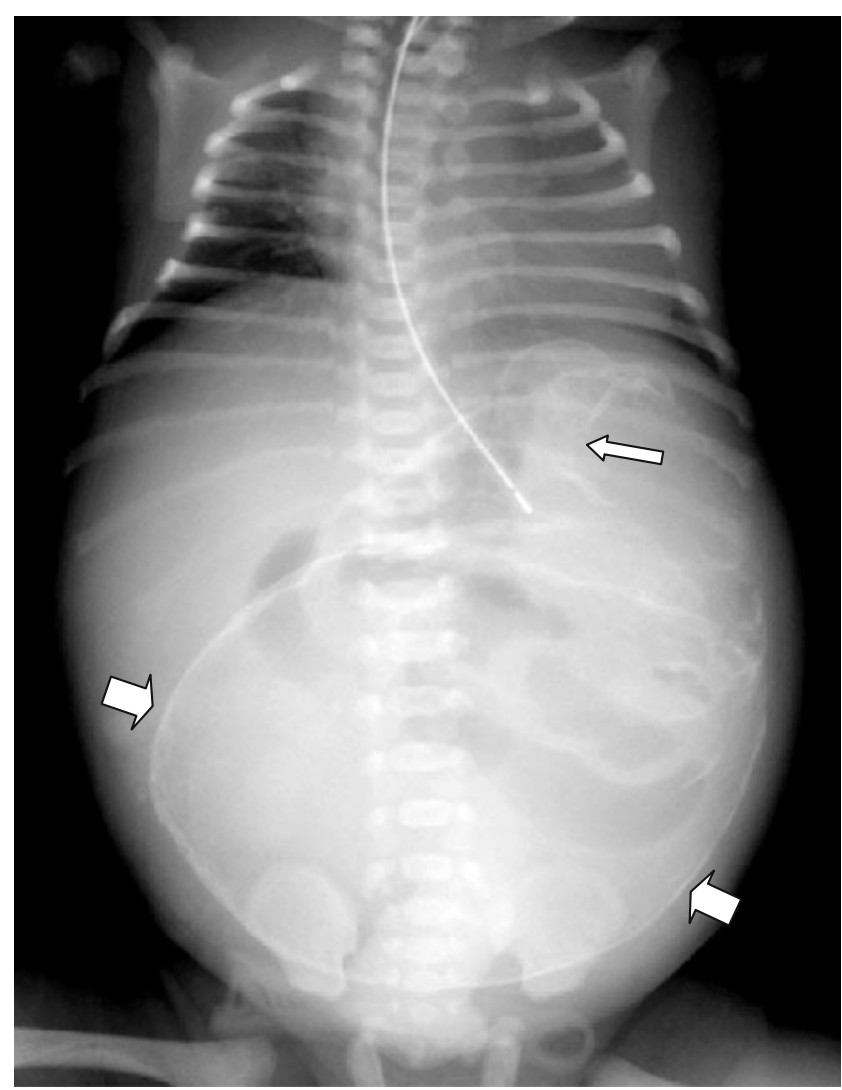

Fig. 1 Supine radiograph of the chest and abdomen

\section{References}

1. Foster MA, Nyberg DA, Mahony BS et al (1987) Meconium peritonitis: prenatal sonographic findings and their clinical significance. Radiology 165:661-665

2. Lee YC, Chen CJ (2009) Meconium pseudocyst: a classical and successfully treated case. J Formos Med Assoc 108:247-252
Department of Radiology,

University of California Davis Medical Center,

4860 Y St.,

Sacramento, CA 95817, USA

e-mail: david.douglas@ucdmc.ucdavis.edu 